\title{
O aperfeiçoamento da leitura e da escrita na formação de professores: uma experiência de ensino-pesquisa no PIBID-geografia
}

\author{
The improvement of reading and writing in teacher training: an \\ experience of teaching and research in PIBID-geography
}

\section{Lenilton Francisco de Assis'}

\section{RESUMO}

O artigo apresenta uma experiência formativa vivenciada em oficinas pedagógicas do Programa Institucional de Bolsas de Iniciação à Docência (PIBID/CAPES), no subprojeto Geografia da Universidade Federal do Rio Grande do Norte (UFRN). Diversas estratégias didático-pedagógicas foram trabalhadas para incentivar a leitura e a produção de textos derivados de pesquisas sobre as práticas escolares. 0 propósito foi desenvolver uma práxis formativa que articulasse teoria e prática, ensino e pesquisa, na formação de professores de Geografia. Os resultados apontam que as ações do PIBID, além de focalizar as atividades de ensino, devem também instrumentalizar a pesquisa e a reflexão na/da escola com o fito de aperfeiçoar a leitura e a escrita para o pleno exercício da profissão docente.

Palavras-chave: Ensino de Geografia; Escrita; Formação de Professores; Leitura; PIBID

\section{ABSTRACT}

The article presents a formative experience lived in pedagogical workshops of the Institutional Program of Teaching Initiation Scholarships (PIBID/CAPES), in the Geography subproject of the Federal University of Rio Grande do Norte (UFRN, Brazil). Several didactic-pedagogical strategies were worked to encourage reading and the production of texts derived from research on school practices. The purpose was to develop a formative praxis that articulated theory and practice, teaching and research, in the formation of Geography teachers. The results indicate that the actions of PIBID, besides focusing the teaching activities, must also instrumentalize the research and the reflection in the school with the purpose of improving the reading and writing for the full exercise of the teaching profession.

Key words: Geography Teaching; Writing; Teacher Training; Reading; PIBID

\section{INTRODUÇÃO}

É pública e notória a dificuldade da leitura e da escrita dos estudantes brasileiros em geral. Este déficit de alfabetização, quando não corrigido nos anos

'Doutor em Geografia Humana pela USP. Professor do Departamento de Metodologia da Educação e do Programa de Pós-graduação em Geografia da UFPB E-mail: lenilton@yahoo.com ORCID: https://orcid.org/0000-0003-40834643 
iniciais de escolarização, compromete a formação básica do aluno e sua vida profissional.

Nas últimas décadas, com a ampliação das vagas no ensino superior, tal problema se expande nas universidades do País e demanda especial atenção nos cursos de licenciatura. Como admitir que alguém que se propõe a ensinar crianças e jovens não saiba interpretar diferentes tipos de gêneros textuais? Que não tenha os conhecimentos mínimos do padrão formal da língua portuguesa? Que não consiga sistematizar um texto argumentativo, nem redigir um projeto ou um artigo sobre a sua prática docente?

A sociedade espera que a universidade forme professores com plena capacidade de atuar nas escolas para que estas continuem sendo espaços privilegiados para o desenvolvimento da leitura e da escrita. Nesse sentido, Borges (2010, p. 202) ressalta que "a leitura propicia ao indivíduo os meios necessários para apropriar-se dos bens culturais registrados pela escrita, visto que essa é característica essencial, própria do ser humano". Mas quando os professores apresentam déficit de alfabetização, a quem cabe enfrentar o problema?

Atento a esta questão, o Programa Institucional de Bolsas de Iniciação à Docência, PIBID/CAPES, no subprojeto Geografia da Universidade Federal do Rio Grande do Norte (UFRN), tem envidado esforços para promover o aperfeiçoamento da leitura e da escrita que contribua para a formação do professor crítico-reflexivo (CAVALCANTI, 2012), ou seja, do professor que busca, nas leituras, referenciais teóricos para melhorar suas pesquisas, seus escritos e seu trabalho.

Assim, apresentamos nesse artigo uma experiência formativa vivenciada em oficinas do PIBID-Geografia da UFRN, onde diversas estratégias didáticopedagógicas foram trabalhadas para incentivar a leitura e a produção de textos derivados de pesquisas sobre as práticas escolares. O propósito foi desenvolver uma práxis formativaii que articulasse teoria e prática, ensino e pesquisa, na 
formação de professores de Geografia. Os resultados demonstram que as ações do PIBID, além de focalizar nas atividades de ensino, devem também instrumentalizar a pesquisa e a reflexão na/da escola com o fito de aperfeiçoar a leitura e a escrita para o pleno exercício da profissão docente.

\section{AS PRÁTICAS FORMATIVAS DO PIBID-GEOGRAFIA DA UFRN: ARTICULANDO ENSINO-PESQUISA, AÇÃO-REFLEXÃO}

Desde 2009, o curso de licenciatura em Geografia do campus Natal participa do projeto institucional do PIBID da UFRN. Em virtude dos bons resultados alcançados, em 2014, na terceira edição do Programa, o PIBIDGeografia foi ampliado com a seleção de 45 bolsistas, 5 supervisores escolares e 4 coordenadores da universidade. De imediato, este crescimento representou um estímulo à construção de novas práticas formativas para o exercício da docência. Mais graduandos, mais escolas e supervisores foram contemplados, expandindo a política de formação inicial e continuada de professores e o impacto da universidade na educação básica.

Porém essa expansão trouxe alguns desafios para a nova coordenação do subprojeto: como dar conta de um grupo tão heterogêneo de escolas, supervisores e bolsistas? Que ações formativas seriam mais indicadas para integrar bolsistas de diversos períodos da graduação e com diferentes experiências de docência? Que produtos gerar com aqueles que ainda estavam iniciando o curso? E o que fazer para que rapidamente se familiarizassem com a leitura, a escrita acadêmica, a pesquisa e a iniciação à docência?

Ciente dessa difícil empreitada, a primeira aposta da nova coordenação (que incluía 3 professores do Departamento de Geografia e 1 professor do Centro de Educação) foi diversificar as atividades do subprojeto por meio da promoção de oficinas pedagógicas que articulassem o planejamento, a instrumentalização, a leitura e a escrita sobre a ação docente. 
A primeira oficina foi a de Planejamento Pedagógico que ocorria semanalmente na UFRN. Ela reunia bolsistas, supervisores e coordenadores que sistematizavam, em planos de aula, as estratégias de ensino a serem desenvolvidas nas escolas selecionadas pelo PIBID-Geografia. Os planos eram apresentados e avaliados por todo grupo, gerando rodas de debates sobre o trabalho pedagógico e o desafio de articular teoria e prática no exercício da docência.

Preocupados com os produtos a serem gerados pelos bolsistas para o trabalho nas escolas, a coordenação também apostou na Alfabetização Cartográfica como tema da segunda oficina. A escolha do tema não foi casual. Resultou do consenso de que a "formação do aluno leitor crítico de mapas e do aluno mapeador consciente" (BRASIL, 1998; SIMIELLI, 2003) eram competências ainda distantes de serem atingidas no ensino de Geografia. As causas desse problema foram apontadas como reflexos da insegurança e sobretudo das deficiências da formação inicial do professor de Geografia. Por isso, havia a necessidade de aperfeiçoar o domínio dos símbolos e significados da linguagem cartográfica para que os bolsistas soubessem, nas práticas escolares, operar a aprendizagem espacial por meio de recursos como mapas, croquis, maquetes, globos terrestres e imagens de satélite.

Já a terceira oficina, a princípio, atendia à recomendação institucional da CAPES para os subprojetos definirem estratégias para o aperfeiçoamento da capacidade comunicativa dos bolsistas e do domínio da língua portuguesa - o que incluía leitura, escrita e fala. Ainda que o domínio de tais habilidades devesse ser construído em todas as práticas formativas do PIBID, foi definida uma oficina específica para promover a leitura e a interpretação de textos (nas áreas de Educação e Ensino de Geografia) que permitissem a construção de um referencial 
teórico-metodológico acessível aos bolsistas em diferentes estágios de formação. Buscava-se também uma instrumentalização mínima para incentivar a pesquisa da prática escolar que ainda era vista pelos bolsistas como algo dissociado das atividades de ensino.

Nesse processo de articulação entre ensino e pesquisa, vale destacar a importante advertência de André (2012, p. 60-61) para o crescente movimento de formação do professor pesquisador:

Querer que o professor se torne um profissional investigador de sua prática exige que se pense nas exigências mínimas para sua efetivação, ou seja: é preciso que haja uma disposição pessoal do professor para investigar, um desejo de questionar; é preciso que ele tenha formação adequada para formular problemas, selecionar métodos e instrumentos de observação e de análise; [...] Esperar que os professores se tornem pesquisadores, sem oferecer as necessárias condições ambientais, materiais, institucionais implica, por um lado, subestimar o peso das demandas do trabalho docente cotidiano e, por outro, os requisitos para um trabalho científico de qualidade iii [Grifo nosso].

Diante desses inúmeros desafios para que a pesquisa se constitua e se viabilize como prática profissional do futuro professor, é preciso, conforme grifado acima, incentivá-la e instrumentalizá-la desde a formação inicial na universidade. Nesse sentido, a terceira oficina de leitura e produção textual buscava articular ensino e pesquisa, ou seja, o domínio e a investigação dos saberes-fazeres planejados na universidade e executados nas escolas.

Ademais, a oficina propunha a discussão e o treinamento de técnicas de redação científica que subsidiassem a escrita reflexiva sobre a ação docente. Nesse processo de ação-reflexão, artigos foram produzidos sobre as práticas escolares revelando boas iniciativas para a melhoria da formação de professores, inclusive para o incentivo da leitura e da escrita. Segundo Borges (2010, p. 202), “[...] a leitura leva à escritura e esta àquela, principalmente, no processo do ensino superior". 


\title{
3.LEITURA E ESCRITA DE ARTIGOS NAS OFICINAS DO PIBID-GEOGRAFIA: A
} PESQUISA COMO MEDIAÇÃO ENTRE A FORMAÇÃO DOCENTE E A PRÁTICA

\section{ESCOLAR}

Ler e escrever são atividades inerentes à profissão docente. Todavia, nos cursos de licenciatura, tais atividades não são comumente direcionadas para desenvolver uma atitude investigativa sobre a prática pedagógica do futuro professor e sobre as condições de trabalho nas escolas. E isso ocorre porque ainda perdura, em muitos currículos, a separação entre ensino e pesquisa, entre teoria e prática.

Uma demonstração desse problema é apontada por Pimenta e Lima (2012, p. 33) que, após anos de estudos, de debates e reflexões sobre a formação de professores, constatam:

\begin{abstract}
Não é raro ouvir, a respeito dos alunos que concluem seus cursos, referências como "teóricos", que a profissão se aprende "na prática", que certos professores e disciplinas são por demais "teóricos". Que "na prática a teoria é outra". No cerne dessa afirmação popular, está a constatação, no caso da formação de professores, de que o curso nem fundamenta teoricamente a atuação do profissional nem toma a prática como referência para fundamentação teórica. Ou seja, carece de teoria e de prática. Na verdade, os currículos de formação têm-se constituído em um aglomerado de disciplinas isoladas entre si, sem qualquer explicitação de seus nexos com a realidade que lhes deu origem.
\end{abstract}

No intento de contribuir para suplantar esse modelo formativo, na oficina de leitura e produção textual, foram desenvolvidas várias estratégias para estimular a interpretação de textos e a correlação com as vivências da prática escolar. Temas de interface entre a Educação e o Ensino de Geografia (tais como Construtivismo, Currículo, Avaliação, Conceitos e Procedimentos de Ensino de Geografia) foram discutidos nos textos visando à construção de um aporte teórico mínimo que direcionasse a ação-reflexão nas escolas (Quadro 1). Entendíamos, semelhante a Pimenta (2010, p. 26), que “o papel da teoria é oferecer aos professores perspectivas de análise para compreenderem os contextos históricos, sociais, culturais e organizacionais e de si mesmos como profissionais, nos quais se dá sua atividade docente, para neles intervir, transformando-os". 


\begin{tabular}{|c|c|c|}
\hline $\begin{array}{l}\text { Descrição sucinta da ação / } \\
\text { atividade }\end{array}$ & Período & Materiais necessários / Produtos gerados \\
\hline $\begin{array}{l}\text { Planejamento geral das } \\
\text { atividades do semestre }\end{array}$ & 2014.1 & stratégia/Recurso: Ficha de Planejamento \\
\hline $\begin{array}{l}\text { Discussão dos fundamentos do } \\
\text { construtivismo e dos tipos e } \\
\text { estruturas de artigos científicos }\end{array}$ & 2014.1 & $\begin{array}{l}\text { Texto 1: ROSA, Sanny S. Construtivismo ou o "novo" } \\
\text { na educação brasileira. In: Construtivismo e mudança. } \\
\text { Cortez, 2002. } \\
\text { Estratégia/Recurso: apresentação de mapas } \\
\text { conceituais elaborados com o software livre Cmap } \\
\text { Tools }\end{array}$ \\
\hline $\begin{array}{llll}\text { Debate sobre } & \text { as } & \text { interações } & \text { e } \\
\text { ambivalências } & \text { entre } & o \\
\text { construtivismo de } & \text { Piaget e } & 0 \\
\text { socioconstrutivsmo de Vygostsky }\end{array}$ & 2014.1 & $\begin{array}{l}\text { Texto 2: BECKER, Fernando. Vygotski versus Piaget - } \\
\text { ou sociointeracionismo e educação. In: Formação de } \\
\text { educadores: desafios e perspectivas. Ed. UNESP, } 2003 . \\
\text { Estratégia/Recurso: discussão dos vídeos "Paradigma } \\
\text { Construtivista na Educação" } \\
\text { <https://www.youtube.com/watch?v=_1zEriZlwQc> e } \\
\text { "Paradigma Socioconstrutivista na Educação" } \\
\text { <https://www.youtube.com/watch?v=-|EU9ZxXSQU> }\end{array}$ \\
\hline $\begin{array}{l}\text { Discussão sobre procedimentos } \\
\text { de ensino de geografia e a } \\
\text { abordagem socioconstrutivista }\end{array}$ & 2014.1 & $\begin{array}{l}\text { Texto 3: CAVALCANTI, Lana. Geografia escolar e } \\
\text { procedimentos de ensino de uma perspectiva } \\
\text { socioconstrutivista. In: O ensino de geografia na } \\
\text { escola. Ed. Papirus, 2012 } \\
\text { Estratégia/Recurso: Estudo dirigido; discussão do } \\
\text { vídeo "Ser Professor - Victor Hugo Duba" } \\
\text { <https://www.youtube.com/watch?v=6SSYt4|4zZ8> }\end{array}$ \\
\hline $\begin{array}{l}\text { Defesa/Acusação sobre } \text { os } \\
\text { pontos e contrapontos do } \\
\text { currículo de Geografia, seus } \\
\text { avanços e retrocessos }\end{array}$ & 2014.1 & $\begin{array}{l}\text { Texto 4: OLIVEIRA, Ariovaldo U. Geografia e ensino: os } \\
\text { PCNs em discussão. In:Geografia em perspectiva. Ed. } \\
\text { Contexto, } 1999 \text {. } \\
\text { Texto 5: STRAFORINI, Rafael. O currículo de Geografia } \\
\text { das séries iniciais. In: O ensino de geografia e suas } \\
\text { composições curriculares. Ed. UFRGS, } 2011 \text {. } \\
\text { Estratégia/Recurso: Juri Simulado }\end{array}$ \\
\hline $\begin{array}{l}\text { Orientações para a produção de } \\
\text { Resumos Científicos }\end{array}$ & 4.1 & $\begin{array}{l}\text { Texto 6: PCNs de Geografia do Ensino Fundamental, } \\
\text { p. 29-34 } \\
\text { Texto 7: VESENTINI, José William. Repensando a } \\
\text { geografia escolar para o século XXI. São Paulo: } \\
\text { Plêiade, 2009. p. } 69-159 \\
\text { Estratégia/Recurso: Resumo }\end{array}$ \\
\hline $\begin{array}{l}\text { Planejemanto, orientação, } \\
\text { escrita e revisão de artigos sobre } \\
\text { as práticas escolares }\end{array}$ & 2014.2 & $\begin{array}{l}\text { Estratégia/Recurso: Resumos e artigos produzidos } \\
\text { pelos bolsistas para apresentação em eventos } \\
\text { científicos }\end{array}$ \\
\hline $\begin{array}{l}\text { Conhecer métodos e técnicas } \\
\text { para a pesquisa da prática } \\
\text { escolar }\end{array}$ & 2014.2 & $\begin{array}{l}\text { Texto 8: LUDKE; Menga; ANDRÉ, Marli. Pesquisa em } \\
\text { Educação: abordagens qualitativas. 2. ed. São Paulo: } \\
\text { IPU, 2013. Caps. } 3 \text { e } 4 \\
\text { Estratégia/Recurso: A partir das leituras, os bolsistas } \\
\text { foram orientados a coletar dados (fotos, entrevistas, } \\
\text { exercícios aplicados) que servissem de fontes de } \\
\text { pesquisa da própria prática escolar. }\end{array}$ \\
\hline
\end{tabular}




\begin{tabular}{|l|c|l|}
\hline $\begin{array}{l}\text { Revisão das normas técnica } \\
\text { para a escrita e a organização } \\
\text { de trabalhos acadêmicos }\end{array}$ & 2014.2 & $\begin{array}{l}\text { Estratégia/Recurso: ABNT para citações e } \\
\text { referências. }\end{array}$ \\
\hline $\begin{array}{l}\text { Discussão dos princípios da } \\
\text { avaliação da aprendizagem e } \\
\text { das diferenças entre avaliação } \\
\text { somativa e formativa na } \\
\text { Geografia }\end{array}$ & 2015.1 & $\begin{array}{l}\text { Texto 9: ZABALA, Antoni. A Prática Educativa: como } \\
\text { ensinar. Porto Alegre: Artmed, 1998, p. 195-221 } \\
\text { Estratégia/Recurso: debate do vídeo "Avaliação da } \\
\text { Aprendizagem: formativa ou somativa?" } \\
\text { <https://www.youtube.com/watch?v=G5VEkMf5Rk> }\end{array}$ \\
\hline $\begin{array}{l}\text { Elaboração de questões e } \\
\text { exercícios para identificar as } \\
\text { competências, habilidades e os } \\
\text { objetivos da avaliação }\end{array}$ & 2015.1 & $\begin{array}{l}\text { Estratégia/Recurso: Ficha de questões a serem } \\
\text { analisadas e elaboradas }\end{array}$ \\
\hline $\begin{array}{l}\text { (Re)Planejar a investigação, fazer } \\
\text { a revisão ou a elaboração de } \\
\text { resumos/artigos sobre a prática } \\
\text { escolar }\end{array}$ & 2015.1 & $\begin{array}{l}\text { Estratégia/Recurso: revisão e incentivo à escrita de } \\
\text { resumos e artigos. }\end{array}$ \\
\hline
\end{tabular}

Fonte: Adaptado pelo Autor dos Relatórios de Atividades do PIBID-Geografia/UFRN, 2014/2015.

Ao mesmo tempo, técnicas de ensino e estudo (como mapa conceitual, estudo dirigido, vídeos e júri simulado) buscaram diversificar a dinâmica de trabalho e facilitar a compreensão dos textos selecionados (Quadro 1). Vale a ressalva de que, no processo de leitura, interpretação e discussão dos textos selecionados, as técnicas de ensino e estudo sempre foram empregadas como mediações para atingir as ações pedagógicas descritas na primeira coluna do Quadro 1. Sendo necessárias, mas não suficientes ao processo didático, elas sempre foram empregadas como meio, nunca como fim, pois, como adverte Veiga (2012; 2013), se convém superar o tecnicismo que procura sobrevalorizar as técnicas de ensino e estudo, também cabe não desmerecer sua importância ou mesmo negá-la no processo de ensino.

Concomitante às leituras e às técnicas de ensino e estudo, outro ponto de atenção da oficina foi com a escrita dos bolsistas cujas dificuldades eram evidentes nas produções textuais até então apresentadas. Alertávamos para a relação existente entre o bom leitor e o bom escritor e sobre os perigos da escrita acadêmica chamada de "colcha de retalhos":

Nela, o pesquisador, por não possuir ainda um discurso escrito próprio, utilizase ou apropria-se do discurso alheio, e ao somar textos, não percebe que muitas vezes estes são desconexos ou conflitantes. Esta dificuldade, que redunda numa escrita fechada e pouco clara, muitas vezes, provém da dificuldade em compreender e interpretar textos. Tão difícil quanto o domínio 
da escrita, não se resolve da noite para o dia, num passe de mágica [...] (FAZENDA, 2010, p. 15-16).

Cientes desses desafios, incentivamos, de início, a produção de resumos críticos que, além de condensarem as ideias centrais dos autores discutidos, também eram acrescidos de interpretações e comentários dos próprios bolsistas. Para ampliar o conhecimento sobre a escrita acadêmica, programamos uma oficinaiv sobre técnicas para a elaboração de resumos científicos (leitura, releitura, paráfrase e síntese). O texto-base dessa oficina, "Aprender e ensinar Geografia", foi selecionado dos Parâmetros Curriculares Nacionais de Geografia (BRASIL, 1998, p. 29-34).

Tais estratégias foram necessárias porque o início do trabalho com leitura e produção textual não foi tarefa fácil, nem para os bolsistas, nem para os mediadores da oficina. Muitos bolsistas eram iniciantes da graduação e tinham grandes dificuldades com a leitura e a produção de textos acadêmicos. Havia resistência, desmotivação para as tarefas exigidas que requeriam, a cada encontro, medidas de conscientização e estratégias diversificadas de trabalho.

Com o início das ações do PIBID nas escolas, a articulação da teoria com a prática pedagógica se efetivava, possibilitando aos bolsistas a ampliação das leituras e da escrita. Propormos, então, a produção de artigos sobre as práticas de ensino, ou seja, de artigos que ajudassem os bolsistas a valorizar a riqueza da experiência profissional e a tornar a prática docente um campo de reflexão teórica estruturadora da ação (ALARCÃO, 1996).

De imediato, foi necessário discutir alguns princípios e procedimentos da pesquisa em Educação (LÜDKE, 2001; FAZENDA, 2010; ANDRÉ, 2012) para o entendimento de que a escola não é só espaço do ensino ou da reprodução do conhecimento. Ela também é lócus da pesquisa e da produção de saberes, inclusive dos saberes experienciais dos docentes (TARDIF, 2002) que são pautados nas experiências do trabalho cotidiano na sala de aula onde os professores constroem habilidades de saber-fazer e de saber-ser. Conforme André (2012, p. 61): 
do curso, ou seja, que ela integre o projeto de formação inicial e continuada da instituição, construídos pelos seus participantes, levando em conta os recursos e as condições disponíveis. Essa perspectiva pode traduzir-se numa organização curricular, em que disciplinas e atividades sejam planejadas coletivamente, com o objetivo de desenvolver habilidades e atitudes de investigação nos futuros professores. Pode, além disso, traduzir-se no uso da pesquisa como mediação, ou seja, que as disciplinas e atividades do curso incluam a análise de pesquisas que retratem o cotidiano escolar, visando aproximar os futuros docentes da realidade das escolas, levando-os a refazer o processo da pesquisa e a discutir sua metodologia e seus resultados.

É essa concepção de professor pesquisador, ou melhor, de “professor críticoreflexivo" que Cavalcanti (2012, p. 78-79) também defende para a formação de professores de Geografia, quando afirma:

Esse entendimento leva, então, a postular a necessidade de articular ensino com pesquisa (que é construção de conhecimento). Está subjacente a essa discussão o entendimento de que a pesquisa pode ser vista como procedimento de ensino, que tanto vale para o ensino fundamental e médio, que promovem a formação geral dos alunos, quanto para os cursos de nível superior, que formam profissionais. [...] O professor crítico-reflexivo é, dessa forma, aquele profissional que tem competência para pensar sua prática com qualidade, crítica e autonomia, tendo como base referenciais teóricos. A formação de professores de geografia pode se pautar por essa concepção de profissional, entendida como aberta à possibilidade de discussão sobre o papel da educação em várias dimensões, para a construção da sociedade e para a definição do papel da geografia na formação geral do cidadão.

Ao passo em que os bolsistas liam e discutiam os textos da terceira oficina, eram desafiados a pensar sobre algo significativo da experiência docente que instigasse a pesquisa, a escrita e sua divulgação. Sessões de orientações também foram agendadas para discutir as ações desenvolvidas nas escolas e indicar referências bibliográficas complementares que subsidiassem teoricamente as investigações, as reflexões e os registros escritos de tais ações.

Alarcão (1996, p. 7) referenda esses procedimentos ao afirmar que:

Quando reflectimos sobre uma acção, uma atitude, um fenômeno, temos como objecto de reflexão a acção, a atitude, o fenômeno e queremos compreendê-los. Mas para os compreendermos precisamos de os analisar à luz de referentes que lhe dêem sentido. Estes referentes são os saberes que já possuímos, fruto da experiência ou da informação, ou os saberes à procura dos quais nos lançamos por imposição da necessidade de compreender a situação em estudo. Desta análise, feita em função da situação e dos referentes conceptuais teóricos resulta geralmente uma reorganização ou um aprofundamento do nosso conhecimento com consequências ao nível da 
acção. É nesta interacção que reside para mim a essência da relação teoriaprática no mundo profissional dos professores [...].

Passada a primeira etapa da terceira oficina, a nova dinâmica de trabalho do PIBID-Geografia foi pautada pela produção de artigos (Quadro 1). Dividimos os bolsistas em dupla e adotamos a sistemática da correção coletiva da primeira versão dos textos. Neste momento de revisão e reescrita dos textos, os bolsistas puderam apreender as qualidades, as deficiências e as normas da redação acadêmica.

Inicialmente, fizemos a troca de textos e pedimos que cada dupla apontasse os erros ortográficos e gramaticais que encontravam nos artigos dos colegas. As normas da ABNT (Associação Brasileira de Normas Técnicas) para citações e referências bibliográficas também foram exigidas nas correções, pois mereceram discussões à parte nas oficinas. Em seguida, todos os artigos passavam pela avaliação do mediador e retornavam aos bolsistas para os ajustes necessários.

$\mathrm{Na}$ segunda etapa das correções, duplas selecionadas apresentaram os artigos na tela do projetor para que todos acompanhassem a leitura na íntegra e fossem discutindo e alterando a redação. Buscávamos, ali, aperfeiçoar a clareza e a coesão textual por meio da reescrita de parágrafos e da discussão de conectores semânticos (de adição, adversidade, causa, tempo, finalidade etc.) que melhorassem o encadeamento das ideias. Esta técnica, embora cansativa para ser usada por todas as duplas, gerou boas discussões que aprimoraram a escrita e a reflexão.

Também preocupadas com a didatização da escrita dos licenciandos, Suassuna e Leitão (2018, p. 21) destacam que "a revisão e a reescrita que dela resulta são práticas próprias de uma abordagem processual e discursiva da escrita e representam um exercício fecundo de reflexão sobre a língua e o dizer".

A instrumentalização para a pesquisa da prática escolar foi outro assunto sempre recorrente nas revisões dos artigos. À medida em que os bolsistas identificavam os problemas da redação, também discutíamos alguns pressupostos epistemológicos e metodológicos da pesquisa em Educação (LÜDKE, 2001; FAZENDA, 2010; ANDRÉ, 2012) e suas interfaces com as crescentes investigações no campo do 
Ensino de Geografia (PINHEIRO, 2005; CAVALCANTI, 2016). Debatemos, em especial, os tipos de pesquisa mais desenvolvidos, a produção de fontes no ambiente escolar, a sistematização e interpretação dos dados ao longo do texto, o uso de questionários, entrevistas, fotos e de exercícios aplicados com os alunos.

Quanto mais desenvolviam a leitura e a escrita, os bolsistas, por conseguinte, familiarizavam-se com a pesquisa escolar. Ao longo do segundo semestre, eles produziram resumos das pesquisas para participar de eventos científicos regionais e locais. No final de 2014, o V Encontro Nacional das Licenciaturas (ENALIC), realizado na UFRN, foi a grande vitrine para as apresentações das práticas formativas de ensino-pesquisa desenvolvidas e sistematizadas na oficina. Este evento também congregava o IV Seminário Nacional do PIBID, tornando-se mais um atrativo para todos os bolsistas submeterem resumos que logo foram aprovados e publicados nos anais do evento (Quadro 2).

\section{Quadro 2 - Resumos e artigos publicados nos anais do ENALIC 2014}

\begin{tabular}{|l|l|c|}
\hline \multicolumn{1}{|c|}{ Resumo } & \multicolumn{1}{|c|}{ Autores } & \multicolumn{1}{|c|}{$\begin{array}{c}\text { Artigo } \\
\text { completo }\end{array}$} \\
\hline $\begin{array}{l}\text { A abordagem significativa da população } \\
\text { nas aulas de Geografia: uma prática do } \\
\text { PIBID-UFRN }\end{array}$ & $\begin{array}{l}\text { Albérico Fabrício Soares } \\
\text { Marianna Leal Rosa de Araújo }\end{array}$ & X \\
\hline $\begin{array}{l}\text { A atividade diagnóstica por intermédio } \\
\text { do jogo Show da Geografia }\end{array}$ & $\begin{array}{l}\text { Roberto José de Oliveira Junior } \\
\text { Sergio Roberto Vidal do Nascimento } \\
\text { Thiago Herbert Cardoso de Melo } \\
\text { Lenilton Francisco de Assis }\end{array}$ & \\
\hline $\begin{array}{l}\text { A charge como linguagem alternativa } \\
\text { para ensinar e aprender Geografia }\end{array}$ & Maria das Dores Emídio da Silva \\
\hline $\begin{array}{l}\text { A poesia que gera o mapa e o mapa que } \\
\text { gera poesia: a literatura de cordel nas } \\
\text { aulas de Geografia }\end{array}$ & $\begin{array}{l}\text { Carla Mirelly Caetano Duarte } \\
\text { Thalita Cristina Barroca da S. Soares } \\
\text { Lenilton Francisco de Assis }\end{array}$ & \\
\hline $\begin{array}{l}\text { A produção de materiais didáticos para o o } \\
\text { ensino de Cartografia: uma prática do } \\
\text { PIBID-Geografia/UFRN }\end{array}$ & $\begin{array}{l}\text { Devid Hallyson da Silva Nascimento } \\
\text { Débora Leyse Medeiros Mendes } \\
\text { Ary Pereira dos Santos Junior } \\
\text { Lenilton Francisco de Assis }\end{array}$ & \\
\hline $\begin{array}{l}\text { Água: tema geográfico para repensar } \\
\text { estratégias de aulas }\end{array}$ & $\begin{array}{l}\text { Ana Moser de Araújo Silva } \\
\text { Débora Leyse Medeiros Mendes } \\
\text { Ary Pereira dos Santos Junior } \\
\text { Lenilton Francisco de Assis }\end{array}$ & \\
\hline
\end{tabular}




\begin{tabular}{|l|l|l|}
\hline $\begin{array}{l}\text { Atividade lúdica na aula de Geografia: } \\
\text { uma prática para o ensino da geopolítica } \\
\text { do século XX e início do século XXI }\end{array}$ & $\begin{array}{l}\text { Nayara Cristina Araújo de Almeida } \\
\text { Lilian Sheila dos Santos Gomes } \\
\text { Lenilton Francisco de Assis }\end{array}$ & \\
\hline $\begin{array}{l}\text { Estudo das bacias hidrográficas de } \\
\text { Natal/RN a partir de experimentos e } \\
\text { maquetes }\end{array}$ & $\begin{array}{l}\text { Jailza dos Reis Inácio } \\
\text { Deyvid Hugo Santiago Bezerra } \\
\text { Inez Ferreira de Paiva Pacheco } \\
\text { Lenilton Francisco de Assis }\end{array}$ & \\
\hline $\begin{array}{l}\text { Interesse, criatividade e parceria na aula } \\
\text { de Geografia: uma prática do PIBID para } \\
\text { a produção de vídeos didáticos }\end{array}$ & $\begin{array}{l}\text { Geralda Sousa de Carvalho Cunha } \\
\text { Rodolfo Boscolo Rodrigues da Silva } \\
\text { Fátima Edilia da Silva }\end{array}$ & X \\
\hline $\begin{array}{l}\text { Literatura de cordel no ensino de } \\
\text { Geografia: uma prática do PIBID/UFRN }\end{array}$ & $\begin{array}{l}\text { Romário Silva Freire } \\
\text { Dayan Muniz Menezes de Oliveira } \\
\text { Lenilton Francisco de Assis }\end{array}$ & \\
\hline $\begin{array}{l}\text { O uso de atividades lúdicas como auxílio } \\
\text { ao ensino da Cartografia: relato de } \\
\text { experiência do PIBID Geografia - UFRN }\end{array}$ & $\begin{array}{l}\text { Victor Henrique Rodrigues Santana } \\
\text { Everton da Silva Brito } \\
\text { Ellen Cristine de Moura Machado } \\
\text { Lenilton Francisco de Assis }\end{array}$ & \\
\hline $\begin{array}{l}\text { O uso de atividades lúdicas no ensino de } \\
\text { Geografia Política }\end{array}$ & $\begin{array}{l}\text { Marlúcio Valenca Tonheiro Neto } \\
\text { Edu Silvestre de Albuquerque }\end{array}$ & \\
\hline $\begin{array}{l}\text { O uso de materiais didáticos como auxílio } \\
\text { ao ensino da Geografia: relato de } \\
\text { experiência do PIBID Geografia - UFRN }\end{array}$ & $\begin{array}{l}\text { Walquíria Almeida de Lima } \\
\text { Wesley Lacerda de Araújo } \\
\text { Fátima Edília da Silva } \\
\text { Lenilton Francisco de Assis }\end{array}$ & \\
\hline $\begin{array}{l}\text { Regionalização brasileira: uma } \\
\text { experiência do PIBID para aprender } \\
\text { brincando }\end{array}$ & $\begin{array}{l}\text { Jusciana do Carmo da Silva } \\
\text { Marta Regina Claudino da Silva } \\
\text { Fátima Edília da Silva } \\
\text { Edu Silvestre de Albuquerque }\end{array}$ & \\
\hline $\begin{array}{l}\text { Resíduos sólidos urbanos: problemas e } \\
\text { possíveis soluções }\end{array}$ & $\begin{array}{l}\text { Cinddinesya da Silva Nogueira } \\
\text { Amanda Silva dos Santos } \\
\text { Lenilton Francisco de Assis }\end{array}$ & \\
\hline
\end{tabular}

Fonte: Adaptado pelo Autor dos Anais do V Encontro Nacional das Licenciaturas - ENALIC, VI Seminário Nacional do Pibid, UFRN, Campus I - Natal/RN, 2014. 1 CD. ISSN: 2318-6771

Nos títulos dos resumos, há uma diversidade de conteúdos e metodologias voltadas para desenvolver uma prática de ensino de Geografia mais significativa e interessante para o aluno. Essa abordagem construtivista dos trabalhos foi legada das reflexões dos primeiros textos da Oficina (Quadro 1). Destaca-se a atenção dada à Cartografia, às atividades lúdicas, aos recursos didáticos diversificados como charge, poesia, experimentos, vídeos, literatura de cordel, maquetes, entre outros.

Porém, dos 14 resumos aprovados, apenas 3 tiveram os artigos completos publicados nos anais do ENALIC (o envio era opcional). Foram várias as 
dificuldades apontadas pelos bolsistas para o não envio dos textos, tais como: problemas de relacionamento e de organização da dupla; falta de tempo para ler e escrever; pouca discussão das vivências nas escolas; falta de revisão e de finalização dos trabalhos. Nesse processo, as duplas ainda contavam com a colaboração dos supervisores escolares que, ao se tornarem coautores dos artigos, faziam a última revisão dos textos para publicação.

Embora os encontros da terceira oficina fossem agendados quinzenalmente, as queixas dos bolsistas eram frequentes quanto às dificuldades para conciliar as atividades do PIBID com as tarefas da graduação. O clamor coletivo sempre gerava bons debates sobre o tempo que hoje é concedido às novas tecnologias (especialmente a internet e as redes sociais) em detrimento daquele dedicado à leitura, à escrita e à reflexão sobre a formação e a profissão docente.

\section{CONSIDERAÇÕES FINAIS}

A experiência de mediar a oficina de leitura e produção textual nos permitiu apontar três sugestões para melhorar a formação de professores de Geografia e o impacto do PIBID nesse processo:

O Programa não pode centrar suas ações apenas na preparação técnica para a sala de aula, na produção de recursos didáticos ou de estratégias de ensino. Ainda que sejam essenciais, é preciso associar a elas a formação críticoreflexiva dos futuros professores, sob o risco de o PIBID não recair na supervalorização da prática dissociada da teoria, ou seja, da técnica que não promove a crítica sobre os sistemas de ensino e nem a autocrítica sobre a própria ação docente.

É necessário intensificar o aperfeiçoamento da leitura e da escrita na formação inicial de professores. A experiência desta oficina evidenciou que as estratégias adotadas foram significativas, principalmente nos momentos de 
revisão e reescrita dos textos em que afloravam ricos debates sobre a articulação entre teoria e prática, entre ensino e pesquisa, a partir da socialização dos erros e acertos entre o escrito e o experienciado.

É preciso incorporar a pesquisa às práticas escolares do PIBID. Para tanto, os bolsistas carecem de instrumentalização adequada para o domínio de métodos e técnicas de pesquisa em Educação, pois nenhuma prática formativa terá êxito se não acompanhada do estímulo à investigação, do esforço de tornar a escola espaço de ação-reflexão.

Não obstante tais conclusões, estamos cônscios de que as estratégias adotadas na terceira oficina não supriram todas as deficiências de leitura e de escrita dos bolsistas do PIBID-Geografia e nem resolvem os dilemas suscitados para a articulação entre o ensino e a pesquisa na formação de professores. Acreditamos, todavia, que se continuadas e aperfeiçoadas, elas podem contribuir para a formação de docentes dotados de autonomia e de criticidade sobre o que leem, escrevem, pesquisam e ensinam.

\section{REFERÊNCIAS}

ALARCÃO, I. Ser professor reflexivo. In: (Org.). Formação reflexiva de professores: estratégias de supervisão. Porto/Portugal: Editora Porto, 1996. p. 171179

ANDRÉ, M. (Org.). O papel da pesquisa na formação e na prática dos professores. 12 ed. Campinas, SP: Papirus, 2012.

ASSIS, L. F. Estágio Supervisionado de Geografia: impressões e estratégias de ensinopesquisa. In.: ASSIS, L. F. de; SOARES JÚNIOR, F. C. (Orgs.). Ensino e Pesquisa na Educação Geográfica. Natal: EDUFRN, 2018 p. 19-47 Disponível em: https://bit.ly/2m49kHW Acesso em: 14 jul. 2018

BORGES, R. C. M. B. O professor reflexivo-crítico como mediador do processo de interrelação da leitura - escritura. In: PIMENTA, S. G.; GHEDIN, E. (Orgs.). Professor reflexivo no Brasil: gênese e crítica de um conceito. 6. ed. São Paulo: Cortez, 2010. p. 233-254 
BRASIL. Ministério da Educação. Parâmetros Curriculares Nacionais - Geografia. Brasília: SEF / MEC, 1998, p. 29-34.

CAVALCANTI, L. S. O ensino de geografia na escola. Campinas, SP: Papirus, 2012.

. Para onde estão indo as investigações sobre ensino de geografia no Brasil? Um olhar sobre elementos da pesquisa e do lugar que ela ocupa nesse campo. Boletim Goiano de Geografia (Online). Goiânia, v. 36, n.3, p. 399-419, set./dez. 2016. Disponível em: https://revistas.ufg.br/bgg/article/view/44546_ Acesso em: 02 mar. 2017.

FAZENDA, I. (Org.). Metodologia da pesquisa educacional. 12. ed. São Paulo: Cortez, 2010.

FONTENELLE FILHO, J. Formação crítico-reflexiva na perspectiva do professor de Geografia: um estudo de caso. Geosaberes - Revista de Estudos Geoeducacionais. v. 1, n. 2, p. 180-197, Dezembro/2010. Disponível em: http://www.geosaberes.ufc.br/geosaberes/article/view/59 Acesso em: 02 mar. 2017.

GERALDI, C. M.; FIORENTINI, D.; PEREIRA, E. M. (Orgs.) Cartografia do trabalho docente: professor(a)-pesquisador(a). Campinas, SP: Mercado de Letras/ABL, 1998.

LÜDKE, M. O professor e a pesquisa. 7. ed. Campinas, SP: Papirus, 2001.

KONDER, L. O futuro da filosofia da práxis: o pensamento de Marx no século XXI. Rio de Janeiro: Paz e Terra, 1992.

PIMENTA, S. G. Professor reflexivo: construindo uma crítica. In: PIMENTA, S. G.; GHEDIN, E. (Orgs.). Professor reflexivo no Brasil: gênese e crítica de um conceito. 6. ed. São Paulo: Cortez, 2010. p. 20-62

PIMENTA, S. G.; GHEDIN, E. (Orgs.). Professor reflexivo no Brasil: gênese e crítica de um conceito. 6. ed. São Paulo: Cortez, 2010.

PIMENTA, S. G.; LIMA, M. S. L. Estágio e docência. 7. ed. São Paulo: Cortez, 2012.

PINHEIRO, A. C. O ensino de Geografia no Brasil: catálogo de dissertações e teses (1967-2003). Goiânia: Vieira, 2005.

NÓVOA, A. (Org.). Os professores e sua formação. Lisboa: Dom Quixote, 1992.

SIMIELLI, M. E. R. Cartografia no Ensino Fundamental e Médio. In: CARLOS, A. F. A. A geografia na sala de aula. 5. ed. São Paulo: Contexto, 2003. p. 92-108

SUASSUNA, L.; LEITÃO, A. K. G. A didatização da escrita por licenciandos do curso de Letras-Português da UFPE. Entrepalavras, Fortaleza, v. 8, n. 3, p. 12-39, out-dez/2018. 
TARDIF, M. Saberes docentes e formação profissional. Petrópolis/RJ: Vozes, 2002.

VEIGA, I. P. A. (Org.). Técnicas de ensino: novos tempos, novas configurações. 3 ed. Campinas, SP: Papirus, 2012.

Novas tramas para as técnicas de ensino e estudo. Campinas, SP: Papirus, 2013.

\begin{abstract}
i Essa formação do professor crítico-reflexivo está baseada nas concepções de "professor pesquisador" e" professor reflexivo" que, nas últimas décadas, têm instigado interessantes debates no campo da formação de professores no Brasil. A fertilidade desses conceitos acena uma nova epistemologia da prática profissional, pois, ao passo em são maturados e instrumentalizados em diversas pesquisas e reflexões (FONTENELLE FILHO, 2010; ASSIS; 2018), também acolhem muitas críticas sobre seu suposto praticismo destituído de teoria e significado político. Sem adentrar nesse debate que foge ao escopo do presente artigo, indicamos as coletâneas organizadas por Geraldi, Fiorentini, Pereira (1998), Pimenta, Guedin (2010) e André (2012) para melhor análise dos potenciais e das críticas a esses conceitos.
\end{abstract}

ii A práxis é aqui entendida como sinônimo de indissociabilidade teoria-prática, como unidade indissolúvel dessas duas dimensões distintas e complementares do processo do conhecimento humano ou, no caso aqui, do processo de formação de professores. De forma mais abrangente, tomamos emprestada a definição de Konder (1992, p. 115) para quem "a práxis é atividade concreta pela qual os sujeitos humanos se afirmam no mundo, modificando a realidade objetiva e, para poderem alterá-la, transformando-se a si mesmos. É a ação que, para se aprofundar de maneira mais consequente, precisa da teoria; é a teoria que remete à ação, que enfrenta o desafio de verificar seus acertos e desacertos, cotejando-os com a prática".

iii Por fim, André (2012, p. 61) ainda faz outro alerta para se "examinar com cuidado essa proposta tão atraente de formar o professor pesquisador para não cair nas suas armadilhas; nem atribuir-lhe um papel redentor, de resolução mágica dos graves problemas educacionais; nem simplificá-la demasiadamente, deixando de considerar as exigências mínimas para sua efetivação. Para evitar esse risco, talvez seja melhor deixar de falar em professor pesquisador de forma genérica e passar a tratar das diferentes maneiras de articular ensino e pesquisa na formação e na prática docente".

iv Nesse primeiro encontro, contamos com a gentil colaboração da Profa. Dra. Erica Eliovitz, então coordenadora do PIBID-Letras da URFN. 